Submitted to J. Geophys. Res.-Atmospheres, August 2004

\title{
The remarkable 2003-2004 winter and other recent warm winters in the Arctic stratosphere since the late 1990s
}

\author{
Gloria L. Manney, ${ }^{1,2}$ Kirstin Krüger, ${ }^{3,4}$ Joseph L. Sabutis, ${ }^{5}$ Sara Amina Sena, ${ }^{2}$ \\ and Steven Pawson 6,7
}

\begin{abstract}
The 2003-2004 Arctic winter was remarkable in the 50-year record of meteorological analyses. A major warming beginning in early January 2004 led to nearly two months of vortex disruption with high-latitude easterlies in the middle to lower stratosphere. The upper stratospheric vortex broke up in late December, but began to recover by early January, and in February and March was the strongest since regular observations began in 1979. The lower stratospheric vortex broke up in late January. Comparison with two previous years, 1984-1985 and 1986-1987, with prolonged mid-winter warming periods shows unique characteristics of the 2003-2004 warming period: The length of the vortex disruption, the strong and rapid recovery in the upper stratosphere, and the slow progression of the warming from upper to lower stratosphere. January 2004 zonal mean winds in the middle and lower stratosphere were over two standard deviations below average. Examination of past variability shows that the recent frequency of major stratospheric warmings (seven in the past six years) is unprecedented. Lower stratospheric temperatures were unusually high during six of the past seven years, with five having much lower than usual potential for PSC formation and ozone loss (nearly none in 1998-1999, 2001-2002 and 2003-2004, and very little in 1997-1998 and 2000-2001). Middle and upper stratospheric temperatures, however, were unusually low during and after February. The pattern of five of the last seven years with very low PSC potential would be expected to occur randomly once every $\sim 850$ years. This cluster of warm winters, immediately following a period of unusually cold winters, may have important implications for possible changes in interannual variability and for determination and attribution of trends in stratospheric temperatures and ozone.
\end{abstract}

\footnotetext{
${ }^{1}$ Jet Propulsion Laboratory, California Institute of Technology, Pasadena, California, USA.

${ }^{2}$ Department of Natural Sciences, New Mexico Highlands University, Las Vegas, New Mexico, USA

${ }^{3}$ Institut für Meteorologie, Freie Universität Berlin, Germany.

${ }^{4}$ Now at Alfred Wegener Institute for Polar and Marine Research, Potsdam, Germany.

${ }^{5}$ School of Education and Department of Computer and Mathematicai Sciences, New Mexico Highlands University, Las Vegas, New Mexico, USA.

${ }^{6} \mathrm{NASA} /$ Goddard Space Flight Center, Greenbelt, MD.

${ }^{7}$ Goddard Earth Science and Technology Center, UMBC, Baltimore, MD
}

\section{Introduction}

The detection and attribution of trends in the Arctic winter stratosphere are among the most complex and important issues in furthering our understanding of climate change and ozone recovery. The Arctic winter stratosphere is thought to be at a threshold where cooler and wetter conditions could lead to severe ozone ioss becoming common [Chipperfield and Pyle, 1998; Waibel et al., 1999; Tabazadeh et al., 2000; WMO, 2003, and references therein]; several indications of decreasing temperature trends have been noted [WMO, 1999, 2003; Ramaswamy et al., 2001, and references therein]. However, large interannual and intraseasonal vari- 
ability in Arctic winter makes detection and attribution of trends extremely challenging. Pawson and Naujokat [1999], hereinafter $P N 99$, and references therein, reported on the unusually cold winters in the mid-1990s, their relationship to past variability, and their consistency with the expected cooling of the lower stratosphere. They noted that the clustering of cold winters may be related to year-to-year randomness, an idea supported by apparent randomness of warm and cold winters in long-term climate model simulations [e.g., Hamilton, 1995; Taguchi and Yoden, 2002], but noted that the cold years seemed to be getting colder. Consistent with this, Rex et al. [2004] concluded that in the cold years the potential for polar stratospheric cloud (PSC) existence throughout the winter has increased in the past $\sim 30$ years in a manner consistent with ozone loss estimates. Several studies suggest increased persistence of the spring Arctic vortex [Waugh et al., 1999; Offermann et al., 2004], but there is no evidence of a clear relationship between midwinter (JanuaryFebruary) vortex strength/coldness and spring persistence [Waugh et al., 1999]. Several studies suggest the existence of weaker/warmer and stronger/colder vortex regimes in the Arctic stratosphere [Perlwitz and Graf, 2001; Perlwitz and Harnik, 2003, and references therein]. Others suggest that anthropogenically caused changes may project on natural modes of atmospheric variability, and thus might be manifested in a change in occurrence frequency of such regimes [e.g., Corti et al., 1999]. Such changes might be consistent with stepwise temperature changes [e.g., Pawson et al., 1998], or with evidence for a shift from weaker/warmer to stronger/colder vortex regimes in the late 1970s [e.g., Christiansen, 2003]. In addition to large uncertainties in observed temperature trends in the northern hemisphere (NH) lower stratosphere, climate model simulations tend to underestimate these trends, and suggest that observed changes in ozone and greenhouse gases (GHGs) may be insufficient to explain the trends [Austin et al., 2003; Shine et al., 2003; $W M O, 2003$, and references therein].

Studies showing substantial cooling trends in the Arctic lower stratosphere have not included the most recent $\mathrm{NH}$ winters, which have been unusually warm and dynamically active. The cold, more quiescent winters studied by Rex et al. [2004] were characterized, among other things, by having no "major" stratospheric warmings [e.g., PN99]. Before 1990 , major warmings occurred about once every two years [e.g., Labitzke, 1982; Naujokat and Labitzke, 1993; Labitzke and Coilaborators, 2002, and references tutereiii]. Duining the 1990s no major warmings occurred in nine consecutive winters [e.g.,PN99; Manney et al., 1999; Labitzke and Collaborators, 2002]. In contrast to this previous behavior, we show below that there have been seven major warmings in fi ve of the past six years. The 2003-2004 winter was par-

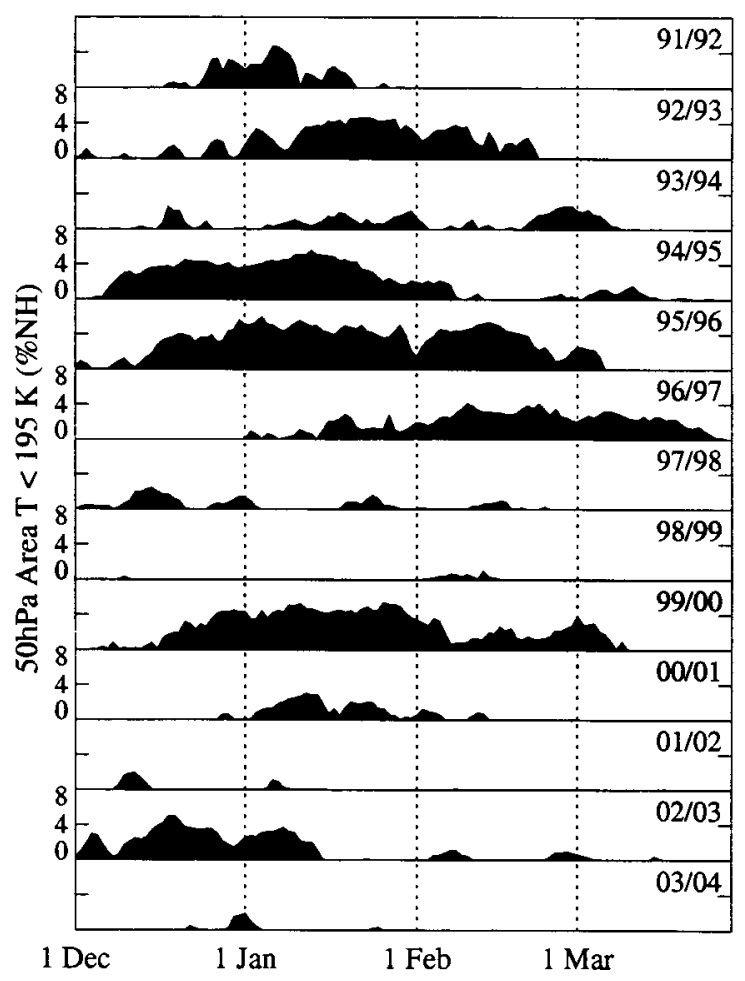

Figure 1. Timeseries of area (percent of northern hemisphere) at $50 \mathrm{hPa}$ with temperatures less than $\mathrm{T}_{\mathrm{NAT}}$ for $1 \mathrm{De}$ cember through through 31 March in 1991-1992 through 2003-2004, from NCEP/CPC analyses. 
ticularly remarkable, with an extended period from early January through mid-February with high-latitude easterlies. The 1999-2000 winter was unusually cold [e.g., Manney and Sabutis, 2000; Rex et al., 2004], but each other winter beginning with 1998-1999 had at least one major warming, with two each in 1998-1999 and 2001-2002 [Manney et al., 1999; Naujokat et al., 2002].

The occurrence of major warmings, especially early in winter, is associated with warmer conditions and hence reduced PSC formation potential following the vortex disruption, as shown in Figure 1. Following the cold winters in the mid-1990s [PN99], only in 1999-2000 and 2002-2003 was there significant ozone loss [Rex et al., 2004, and references therein] in the past seven years. The 2002-2003 early winter was unusually cold, but a major warming in late January was followed by two nearly major warmings in mid-February and early-March, so potential for ozone loss was cut off by late January [after which largest ozone loss typically occurs, e.g., $W M O, 2003$, and references therein]. The 1997-1998 winter was also warm, although no major warmings occurred [e.g., PN99]. We examine here the unusual behavior of the stratosphere in recent winters, focusing on 2003-2004, in the context of the previous record of interannual variability in Arctic polar vortex conditions, and with an eye to the consequences of this behavior for deducing and attributing trends. Several gridded meteorological datasets have been examined and are used herein, depending on their appropriateness for the specific application, as described in the Appendix and discussed further there. We focus on the "satellite era" since 1978-1979 when operational satellite data have been routinely used to constrain stratospheric temperatures in the analyses.

In section 2 we detail the synoptic evolution during the 2003-2004 NH winter in comparison with two winters with some similar characteristics. The recent winters are shown in the context of interannual variability in section 3 . Section 4 provides a summary and discussion. This work extends that of $P N 99$, documents the recent warm Arctic winters (focusing on 2003-2004), and characterizes interannual variability including these years, providing background for future studies of variability and trends in Arctic vortex characteristics and ozone loss.

\section{Synoptic Evolution in the 2003-2004 Arctic Winter and Comparison with 1984-1985 and 1985-1986}

Examination of the meteorological analyses and studies thereof in the past 50 years, [e.g., Labitzke, 1982; Naujokat and Labitzke, 1993] shows only two winters since 19781979 with prolonged midwinter warming periods that may be comparable to that in 2003-2004: 1984-1985 [also described by Randel and Boville, 1987] and 1986-1987. We compare the evolution of the polar vortex in 2003-2004 with that in these two winters to highlight the remarkable behavior in 2003-2004.

Figure 2 shows $10 \mathrm{hPa}$ zonal mean winds and wave 1 and wave 2 in geopotential height for these three winters. High latitude easterlies in 2004 lasted nearly two months, from the beginning of January through late February. High latitude easterlies lasted approximately one month in the other years shown, from late December through January in 19841985 and from late January through late February in 1987 (but with a larger region of easterlies during that period). After the return to westerlies in 2004, the vortex recovered to become unusually strong for late winter; similar behavior was seen in 1985 when the warming period was also early, though the final warming was much earlier (at a more typical time); in 1987, the mid-stratospheric vortex never recovered to a typical mid-winter character. The major warming that began in late December 2003 was preceded by a very large wave-1 amplification. In mid-January 2004 a wave-2 amplification (more prominent at lower altitudes, not shown) led almost immediately to another prolonged wind reversal (though not quite a major warming) and the splitting of the lower stratospheric vortex (see below). A similar pattern was seen in 1987, but with a stronger wave 2 pulse in late January following the wave 1 pulse, and the major warming criteria fulfilled throughout the period. The 1984-1985 major warming, in contrast, was initially a "wave 2 " type warming, with the second warming pulse triggered by wave-1 amplification.

Figure 3 shows the accompanying evolution of north pole temperatures. In 2004, low temperatures were quickly reestablished at high altitudes after mid-January, and by early February (while winds were still easterly) mid-stratospheric temperatures were comparable to those before the warming. This is in contrast to the previous years with prolonged warmings: In 1985, low temperatures were quickly reestablished at high altitudes, but in the middle stratosphere prewarming values were reached only after the westerly vortex had returned; in 1987, when the warming period was later, prewarming temperatures were never re-established in the middle stratosphere. Lower stratospheric temperatures after the warming remained unusually high for the remainder of the winter in all three years. Thus, as will be seen below, while the character of these ulire piolonged wamining periods was quite different in detail, the effect on lower stratospheric temperatures was similar.

Maps of sPV [potential vorticity scaled in "vorticity units", e.g., Dunkerton and Delisi, 1986; Manney et al., 1994b] (Figure 4) show the synoptic evolution of the vortex and tem- 


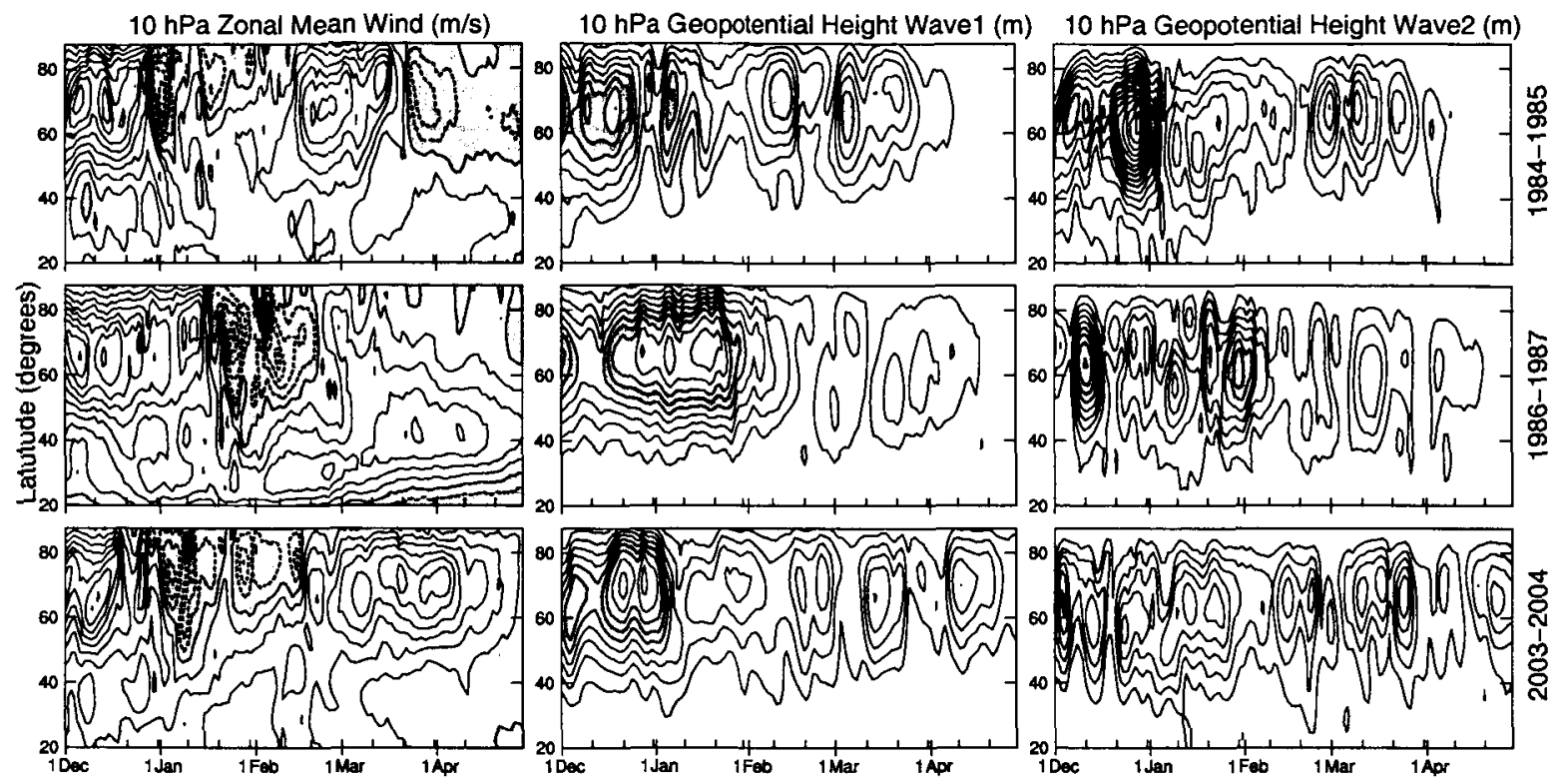

Figure 2. Timeseries for 1 December through 30 April of zonal mean wind (left) and wave 1 (center) and wave 2 (right) geopotential height amplitudes at $10 \mathrm{hPa}$ in 1984-1985 (top), 1986-1987 (middle) and 2003-2004 (bottom). 1984-1985 and 1986-1987 are from ERA-40 data; 2003-2004 is from operational ECMWF data. Zonal mean wind contour interval is $6 \mathrm{~m} / \mathrm{s}$ with negative values shaded; wave 1 contour interval is $150 \mathrm{~m}$, with shading from 750 to $1050 \mathrm{~m}$; wave 2 contour interval is $75 \mathrm{~m}$, with shading from 450 to $750 \mathrm{~m}$.

peratures during the 2003-2004 winter in the upper $(1700 \mathrm{~K}$, $\sim 50 \mathrm{~km})$, middle $(850 \mathrm{~K}, \sim 30 \mathrm{~km})$ and lower $(520 \mathrm{~K}$, $\sim 20 \mathrm{~km}$ ) stratosphere. The vortex began to shrink and shift off the pole by 11 December in the upper stratosphere, and by 19 December (not shown) in the middle stratosphere; by 27 December (Figure 4), the vortex had broken down and easterlies appeared (see below) in the upper stratosphere, while it had shrunk appreciably but not decreased in depth or strength in the middle stratosphere; in the lower stratospheric the vortex shifted off the pole, but continued to gradually strengthen through this date. $10 \mathrm{hPa} 60^{\circ} \mathrm{N}$ winds became easterly on $\sim 2$ January (Figure 2 ), and by 8 January (Figure 4), the middle stratospheric vortex was a weak crescent near $40^{\circ} \mathrm{N}$, with a large region of high temperatures near the pole, very similar to the pattern at the peak of the December 1998 major warming [Manney et al., 1999]. The vortex had weakened slightly and shifted further off the pole in the lower stratosphere, while in the upper stratosphere it began recover. By is Jauiuary, the vortex in the upper stratosphere had recovered to a strength, size and pole-centered position typical of a strong NH midwinter vortex, and did not begin to weaken again until mid-March. In contrast, the vortex weakened even further in the middle stratosphere and split into two fragments (consistent with the wave 2 amplification seen in Figure 2), and continued to weaken gradually in the lower stratosphere. On 1 February, the lower stratospheric vortex split, with the eastern-most fragment rapidly weakening and then coalescing again with the western fragment by 17 February. During this period, the vortex also reformed in the middle stratosphere, but remained extremely weak, only beginning to strengthen substantially after $\sim 23$ February (not shown); lowest temperatures at $850 \mathrm{~K}$ moved back near the pole by 1 February, and by 17 February (although the vortex was still disrupted) were lower than before the warming. By 20 March, the vortex had recovered to a size, strength and coldness greater than usual for March in the middle stratosphere, while it strengthened only slightly and remained very small and weak for the rest of the winter in the lower stratosphere; the upper stratospheric vortex by 20 March had begun to weaken prior to the final warming. The long period when the vortex was strong in the upper stratosphere but very small and weak in the lower to middle stratosphere was quite uncommon. The final warming was late, with $10 \mathrm{hPa}$ zonal mean easterlies appearing only at the end of April, as discussed further in section 3.

Figure 5 shows cross-sections of zonal mean winds on the same days as in Figure 4, illustrating the relatively brief appearance of easterlies recovering to a strong westerly jet by mid-January in the upper stratosphere, and the very pro- 


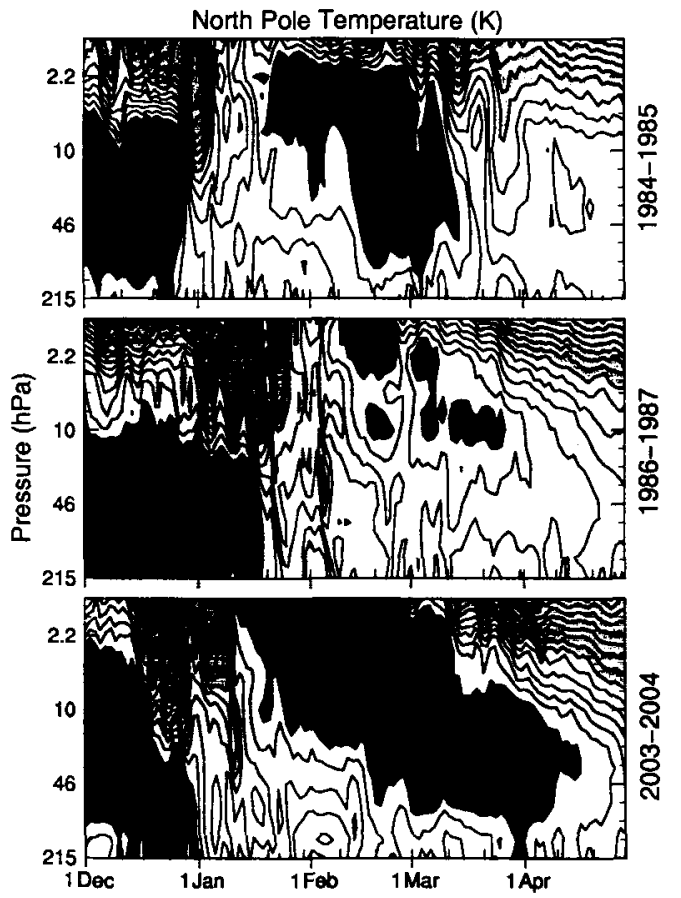

Figure 3. Timeseries for 1 December through 30 April of $90^{\circ} \mathrm{N}$ temperatures $(\mathrm{K})$ as a function of pressure in 19841985, 1986-1987 and 2003-2004 (top to bottom). 1980's fields are from ERA-40 data, 2003-2004 from operational ECMWF. Contour interval is $5 \mathrm{~K}$, with light shading above $240 \mathrm{~K}$ and dark shading below $210 \mathrm{~K}$. longed period of high-latitude easterlies in the middle and lower stratosphere. High latitude zonal mean winds returned to westerly at $10 \mathrm{hPa}$ in mid-February, and to very weak westerlies in the lower stratosphere only at the end of February.

1700,850 and $520 \mathrm{~K}$ sPV maps similar to those in Figure 4 are shown in Figure 6 during the 1984-1985 and 19861987 winters, a few days after the major warming condition was fulfilled (comparable to 8 January 2004), and well into the recovery, but when the vortex was still weak in the middle stratosphere (comparable to 17 February 2004). Figure 7 shows cross-sections of zonal mean winds on the same days. In contrast to 2004, when the vortex already showed signs of recovery in the upper stratosphere when the major warming condition was fulfilled in the middle stratosphere, the recovery was not as rapid in the upper stratosphere in either 1985 or 1987 . The vortex in the lower stratosphere shortly after the peak of the warming ( 3 January 1985, 26 January 1987, compared to 8 January 2004) was more disrupted in 1985 and 1987 than in 2004, with strong easterlies extending further into the lower stratosphere (especially during the wave2 warming in 1985). The behavior seen in these earlier years is more typical of that during major warmings [e.g., $\mathrm{Nau}$ jokat and Labitzke, 1993; Manney et al., 1994a, 1999; Naujokat et al., 2002, and references therein]. During the recovery, the patterns were more similar between the years, but the vortex did not recover as strongly in the upper stratosphere, especially in 1987 when the warming period was later. Also, the vortex in 1985 recovered much more substantially in the lower stratosphere than in either 2004 or 1987; this (as well as the very strong easterlies extending through the lower stratosphere before the recovery) may be more characteristic of a wave 2 warming, as weak recovery in the lower stratospheric has also been reported after other early wave 1 warmings [e.g., Baldwin and Dunkerton, 1989; Manney et al., 1999; Naujokat et al., 2002, and references therein]. Overall, the synoptic behavior during the prolonged 2003-2004 warming period was remarkable, even compared to the most similar previous events.

\section{Interannual Variability and the Historical Context}

We now examine 2003-2004 and the other recent warm $\mathrm{NH}$ winters in the context of previous patterns of interannual variabiiity, focuising on the past 26 years, when operational satellite data have been included in the meteorological analyses.

An overview of $10 \mathrm{hPa}$ high latitude zonal mean winds for 1978-1979 through 2003-2004 is given in Figure 8. 1985 is the only other year in the record with a prolonged period 

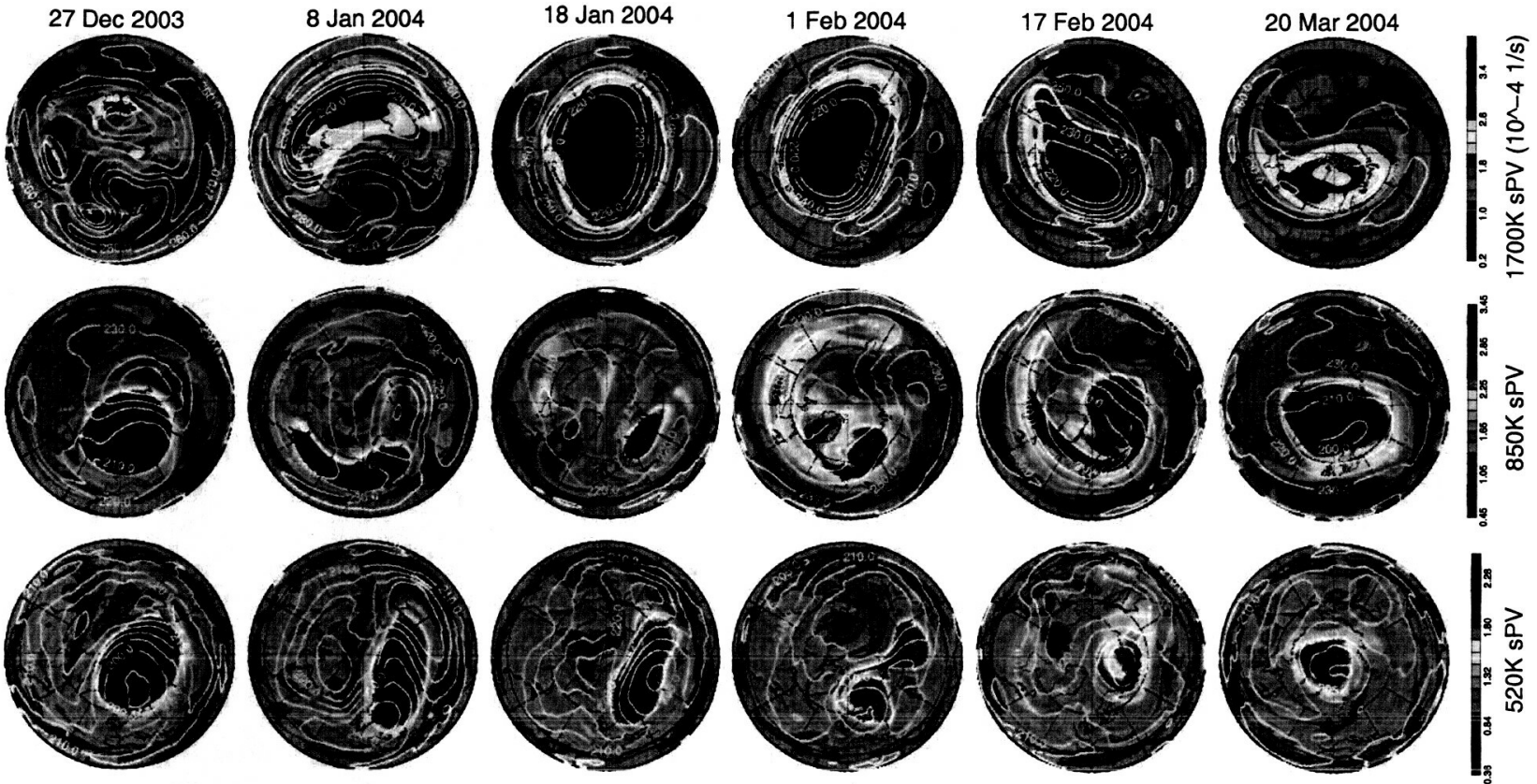

Figure 4. 1700,850 and $520 \mathrm{~K}$ (top to bottom) sPV $\left(10^{-4} \mathrm{~s}^{-1}\right)$ maps with overlaid temperature contours on $27 \mathrm{Decem}-$ ber 2003, 8, 18 January, 1, 17 February, and 20 March 2004. Temperature contours are 220 to $280 \mathrm{~K}$ by $10 \mathrm{~K}$ at $1700 \mathrm{~K}, 200$ to $260 \mathrm{~K}$ by $10 \mathrm{~K}$ at $850 \mathrm{~K}$ and 195 to $225 \mathrm{~K}$ by $5 \mathrm{~K}$ at $520 \mathrm{~K}$. Fields are from GEOS- 4 analyses. Domain is from equator to pole with dashed circles at $30^{\circ}$ and $60^{\circ} \mathrm{N} ; 0^{\circ}$ longitude is at the bottom and $90^{\circ} \mathrm{E}$ to the right.

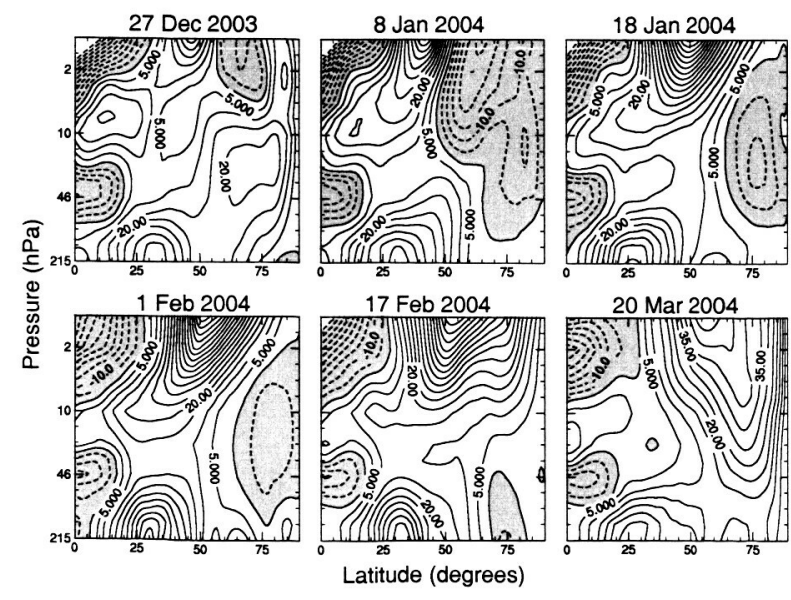

Figure 5. Latitude-pressuirc crosss-scctioñns of zoniâl mîcân wind on 27 December 2003, 8, 18 January, 1, 17 February and 20 March 2004, from GEOS-4 analyses. Contour interval is $5 \mathrm{~m} / \mathrm{s}$, with values less than zero shaded. of easterly or near-zero winds in January, and 1987 the only other year with a comparably prolonged midwinter period of easterly winds. Midwinter easterlies at $60^{\circ} \mathrm{N}$ indicate major warmings - these occurred in December 1998, February 1999, February 2001, December 2001, February 2002, January 2003, and January 2004, a total of seven in fi ve of the past six winters. There is no other period since 19781979 with as much warming activity; the most similar period is 1983-1984 through 1988-1989 when there were fi ve major warmings in six years, and several of those were early (e.g., December 1987) or late (e.g., late February 1984) in winters with otherwise strong, cold vortices. Examination of the long-term reanalyses (ERA-40 to 1957 and REAN to 1948 , not shown) and FUB dataset indicate one other period with fi ve major warmings in six years (1967-1968 through 19721973) and one other prolonged warming period in January (a "wave-1" warming in January 1970). As noted by Naujokat et al. [2002], many of the recent stratospheric warmings have been atypicaily eariy (tinree in D̃ecemberieariy January and one in mid-January), in contrast to the more typical occurrence in February before the 1990s [e.g., Naujokat and Labitzke, 1993; Labitzke and Collaborators, 2002]. However, the unusual frequency of major warmings in recent years has not resulted in earlier final warmings - in fact, the earliest 

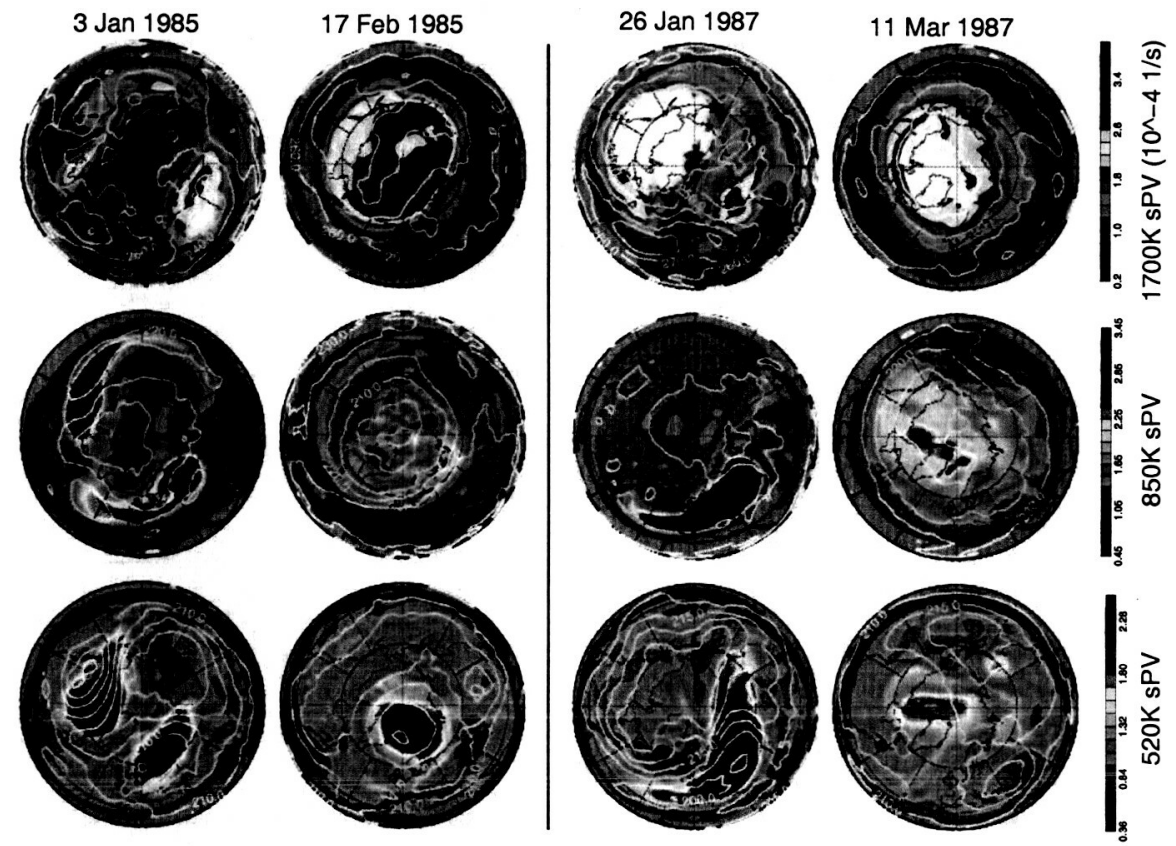

Figure 6. 1700,850 and $520 \mathrm{~K}$ (top to bottom) sPV maps $\left(10^{-4} \mathrm{~s}^{-1}\right)$ with overlaid temperature contours on 3 January and 17 February 1985 (left two columns) and 26 January and 11 March 1987 (right two columns). Data are from ERA-40 analyses; blank regions at $1700 \mathrm{~K}$ are where that level is above $1 \mathrm{hPa}$, the top level provided in the ERA-40 fields. Layout is as in Figure 4.

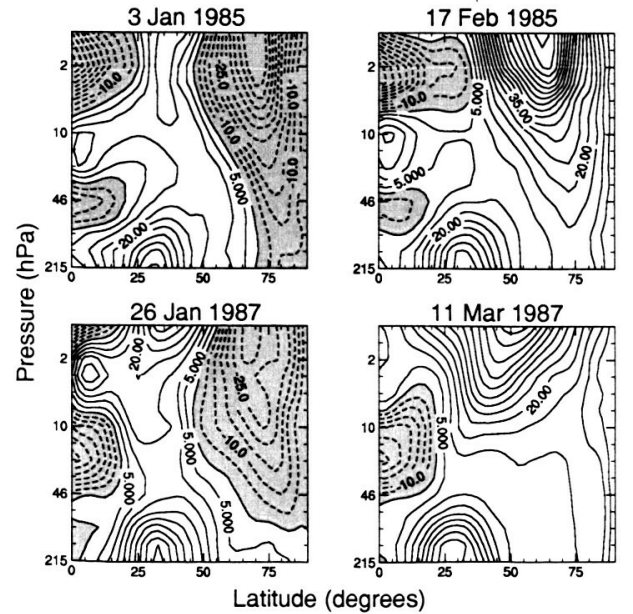

Fightre 7. Lâtitude-pressure cross-sections of zonai mean wind on 3 January and 17 February 1985 (top) and 26 January and 11 March 1987 (bottom), from ERA-40 analyses. Contour interval is $5 \mathrm{~m} / \mathrm{s}$, with values less than zero shaded. spring vortex breakup (seen in Figure 8 in the final reversal to easterlies) in the past six years was in 2000 , the one cold year. The 2004 final warming was very late, with only 1997 and 1990 (two very cold winters) comparable. Thus in spite of their overall warmth and strong dynamical activity in January and February, the recent winters appear to continue the previously noted [e.g., PN99; Waugh et al., 1999; Labitzke and Collaborators, 2002; Offermann et al., 2004] trend toward later spring vortex breakups. This is consistent with the results of Waugh et al. [1999] who found no relationship between midwinter vortex characteristics and spring vortex persistence. More detailed analyses of the spring trends in recent years are in progress.

The uniqueness of 2003-2004 even among the recent warm winters is underscored in the time series of January and February average monthly mean $60-80^{\circ} \mathrm{N}$ winds in the upper, middle and lower stratosphere and their frequency distribution in the middle stratosphere (Figure 9). January $2004 \mathrm{iO} \mathrm{hFa}$ winds were the lowest in the record, and $50 \mathrm{hPa}$ winds were similarly low only in 1984-1985, with both being over two standard deviations below the 19792004 average. Easterlies were present in a large region throughout the middle and lower stratosphere in the January 2004 mean, with only January 1985 having easterlies in a 


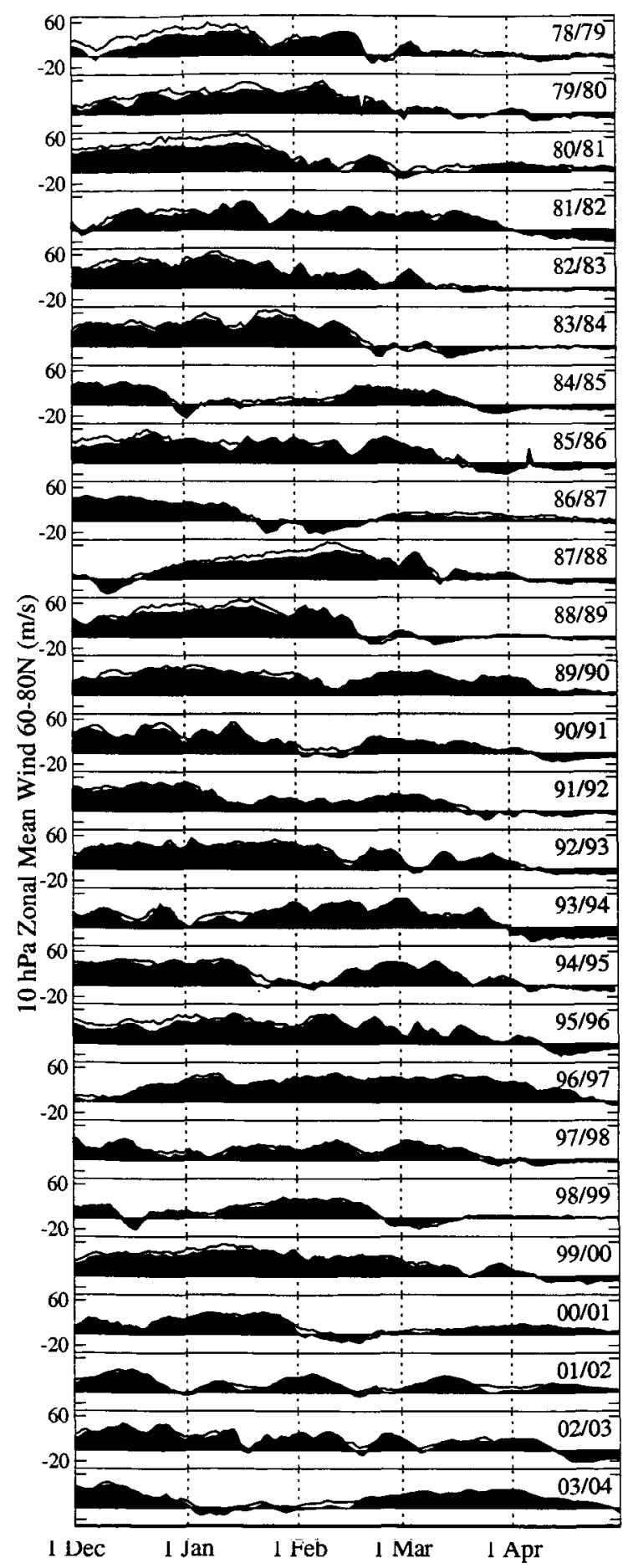

Figure 8. $10 \mathrm{hPa}$ average $60-80^{\circ} \mathrm{N}$ zonal mean winds (cyan and magenta shading for westerlies and easterlies, respectively) and $60^{\circ} \mathrm{N}$ zonal mean wind (black curve) during the past 26 Arctic winters from NCEP/CPC analyses. similar area, and those easterlies were about half as strong as in 2004 (not shown). The frequency distribution of $10 \mathrm{hPa}$ January winds is strongly peaked at values above $30 \mathrm{~m} / \mathrm{s}$, compared to $\sim-4 \mathrm{~m} / \mathrm{s}$ in 2004 , and three other recent winters with values from $10-20 \mathrm{~m} / \mathrm{s}$. Further, 10 and $50 \mathrm{hPa}$ winds in February 2004 were still very low (over one standard deviation below average). The February $10 \mathrm{hPa}$ frequency distribution is sharply peaked at $20-30 \mathrm{~m} / \mathrm{s}$, while 2004 values were under $10 \mathrm{~m} / \mathrm{s}$. In the February 2004 mean, there was a substantial region of weak easterlies in the lower stratosphere; 1987 and 2001 were the only other years in the satellite era with high-latitude easterlies in the February mean, resulting from strong major warmings in February. These two years had much higher January winds than 2004; thus 2003-2004 stands out as having the weakest polar vortex in the middle and lower stratosphere throughout the midwinter period. Note that while $2 \mathrm{hPa}$ winds were unusually low in January 2004 (nearly two standard deviations below average), by February they were among the highest in the record (over a standard deviation above average), reflecting the rapid redevelopment of a strong upper stratospheric vortex; by March (not shown), the 2004 upper stratospheric winds were the strongest on record $(\sim 45 \mathrm{~m} / \mathrm{s}$, compared to the previous maximum in 1996-1997 [the year with the most persistent Arctic vortex, e.g., Waugh and Rong, 2002] of $\sim 35 \mathrm{~m} / \mathrm{s}$ ); March $200410 \mathrm{hPa}$ winds were also strong, reflecting the late final warming (not shown).

The dynamical activity shown above is reflected in temperatures, though not in a simple one-to-one manner. Figure 10 shows the number of days in each year with temperatures low enough for NAT or ice PSC formation at $50 \mathrm{hPa}$, and the average area over the season (December through March) where temperatures were low enough for NAT PSC formation (note that the latter is essentially the same diagnostic as PN99's A $\tau$, except scaled by the fix ed number of days in the season). The recent winters stand out here, with three of the last seven (1998-1999, 2001-2002 and 20032004 , those with the earliest major warmings) having only a few days conducive to PSC formation; the average area where PSCs could form in these years is near zero, and over one standard deviation below the 1978/79-2003/04 average. The only other year in the satellite era comparable to these three was 1984-1985. Two other years in the last seven, 1997-1998 and 2000-2001, also had unusually low (near one standard deviation below average) integrated areas where PSCs could form. A Monte Carlo simulation of these data suggests that the pattern seen between 1997-1998 and 2003-2004 would occur randomly once every 853 years. ${ }^{1}$

\footnotetext{
${ }^{1}$ Although the observed time series is not random (because the minimum number of days is limited to zero), it was assumed to be normally distributed with mean and variance estimated from the data. The estimate was obtained
} 


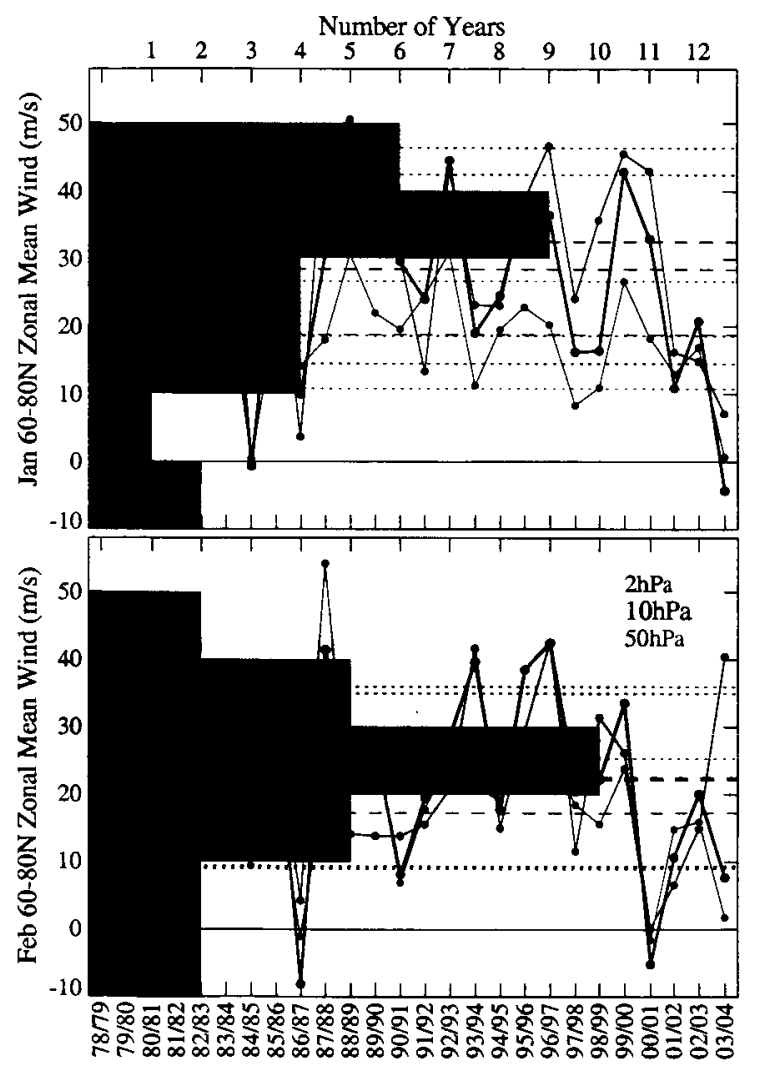

Figure 9. Monthly average $60-80^{\circ} \mathrm{N}$ zonal mean wind at 2 (blue), 10 (black) and 50 (green) hPa during January (top) and February (bottom) as a function of year, with underlying histogram of frequency in years at $10 \mathrm{hPa}$, from NCEP/CPC analyses. Thin dashed lines show 1978/79-2003/04 average, and thin dotted lines the one standard deviation envelope, in colors corresponding to the level.
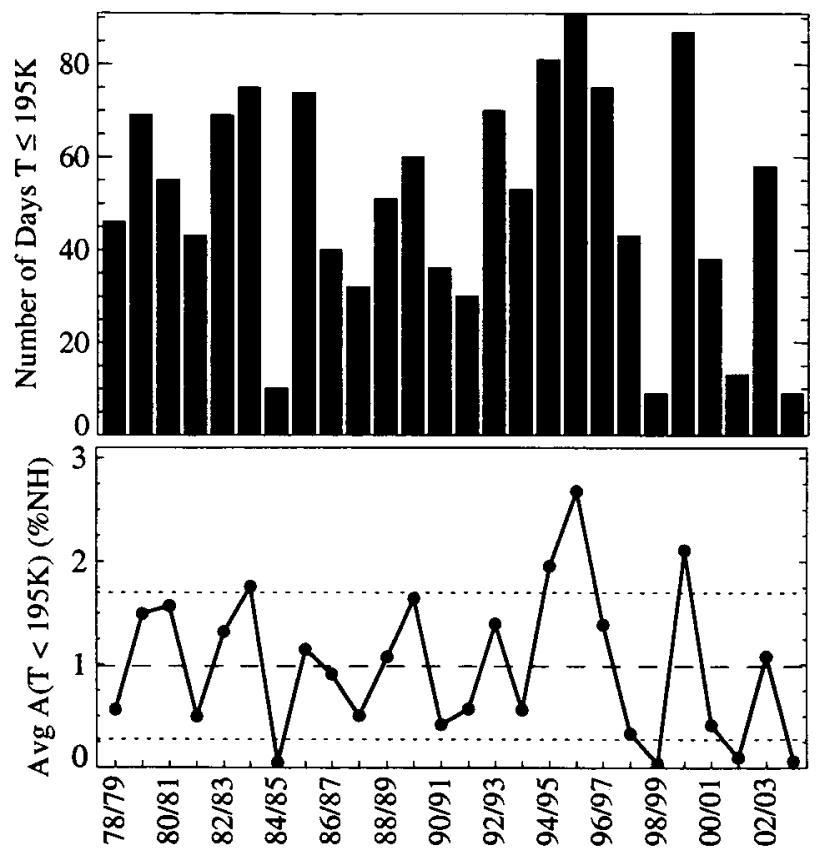

Figure 10. Number of days with $\mathrm{T} \leq 195 \mathrm{~K}$ (grey) and $\mathrm{T} \leq 188 \mathrm{~K}$ (black) at $50 \mathrm{hPa}$ during the past 26 Arctic winters (top), and average area with $\mathrm{T} \leq 195 \mathrm{~K}$ over December through March (bottom), from NCEP/CPC data. Thin dashed line in lower panel shows 1978/79-2003/04 average, and thin dotted lines the one standard deviation envelope.

In the long-term reanalyses and in the historical FUB data (see Appendix), a similarly warm period is apparent in 19651966 through 1970-1971, coinciding approximately with the previous cluster of frequent major warmings.

As noted by $P N 99,1992-1993$ and 1994-1995 through 1996-1997 stand out as unusually cold, as does 1999-2000. Excepting 1999-2000, the past seven years had remarkably little potential for PSC formation and hence ozone loss. The average potential for PSC formation in the individual months of January and February is highlighted in Figure 11. The high PSC formation potentials in 1992 through 1997 stand out in both months. Also striking is the recent cluster of warm years and how different the expectation for PSC formation potential in January and February appears (background histograms) when the past seven years are included in the series - the recent years more than double the frequency of lowest PSC potentials in January and nearly dou-

by tallying in each simulation the number of years until fi ve out of seven consecutive years occurred that deviated from the mean with a value lower than the average of the lowest $f i$ ve of the last seven points in Figure 10. 50,000 simlutations were performed and averaged. Because of the zero-day lower bound on the data, this estimate should be taken as a lower limit. 
ble it in February. While these patterns would appear somewhat less extreme in the full 50-year record (which includes the warm years in the late 1960s), the recent pattern is nevertheless quite extraordinary. A Monte Carlo simulation of the detrended February data suggests that the pattern of three extremely warm years in succession between 2001-2002 and 2003-2004 would occur randomly once every 556 years, while the pattern of six extremely warm years during the seven years 1997-1998 through 2003-2004 would occur randomly once every 12,908 years. ${ }^{2}$

To give an overview of the temperatures throughout the stratosphere, Figure 12 shows time series of monthly average north pole temperatures for January and February at 50 , 10 and $2 \mathrm{hPa}$; other diagnostics, such as minimum and 60$90^{\circ} \mathrm{N}$ average temperatures, exhibit similar patterns. High latitude $50 \mathrm{hPa}$ temperatures were unusually high in the past three years and 1998-1999 in January, and the past four years and 1998-1999 in February, with January 2004 temperatures matching the previous highest in 1985 . $50 \mathrm{hPa}$ north pole temperatures in January and February 2004 were over a standard deviation above average. In the middle stratosphere, 2004 temperatures were unusually high only during January, consistent with the synoptic evolution shown in section 2 . In keeping with the brief disruption and rapid recovery of the vortex in the upper stratosphere, $2 \mathrm{hPa}$ temperatures were lower than usual in both January and February 2004 (February the lowest in the 26-year record, over three standard deviations below average). Similar behavior, albeit less extreme, was seen in January/February 1985 and in February 1987 following those prolonged warming periods, and in the other recent years with early warmings (1998-1999 and 2001-2002). This pattern of strong redevelopment of the upper stratospheric vortex has been seen in previous studies of stratospheric warmings [e.g., Labitzke, 1972; Naujokat and Labitzke, 1993; Labitzke and van Loon, 1999, and references therein]. Over the full winter (not shown), 2003-2004 lower stratospheric high-latitude temperatures were anomalously high, and upper and middle stratospheric temperatures atypically low. High temperatures in March are consistent with the relationship found by Newman et al. [2001] between January-February wave activity (very high during strong stratospheric warmings) and March lower stratospheric temperatures, though they do not, as shown above, indicate a shorter winter.

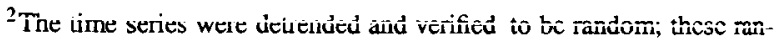
dom series were assumed to be normally distributed, with mean and variance calculated from the data. 50,000 simlutations were performed and averaged in both cases.
}

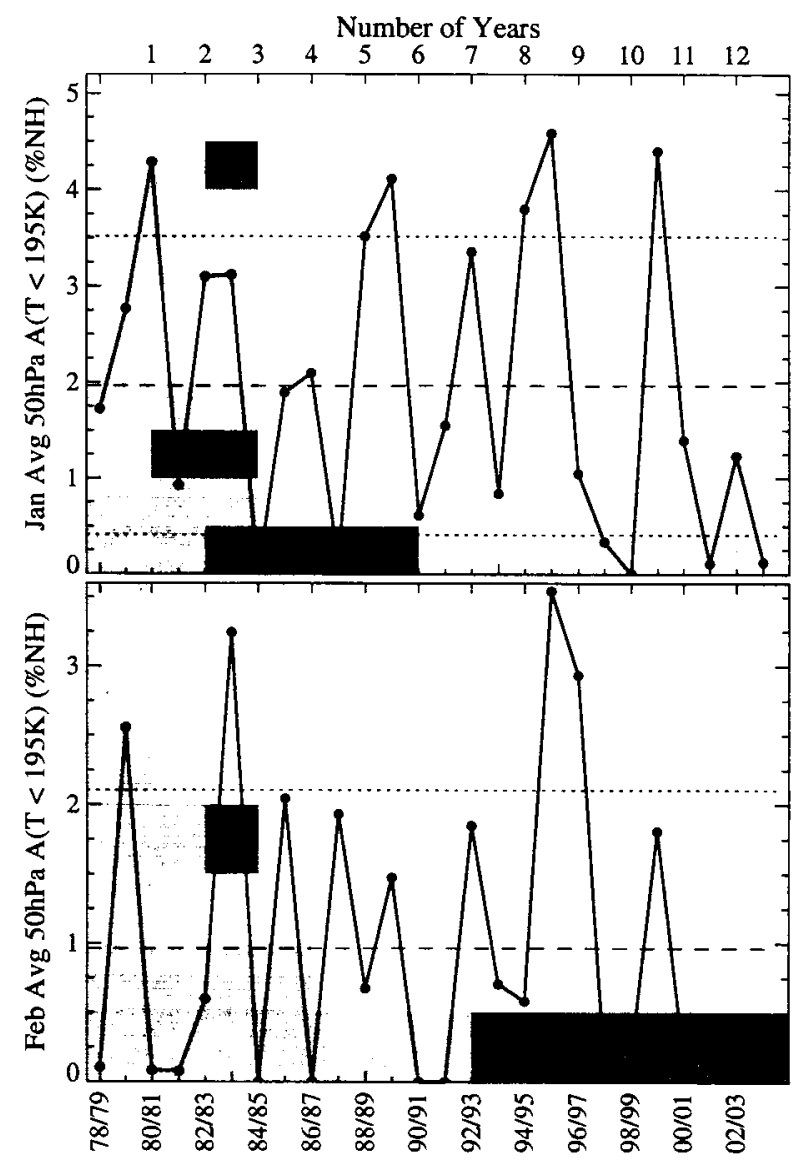

Figure 11. Monthly average area with $\mathrm{T} \leq 195 \mathrm{~K}$ at $50 \mathrm{hPa}$ during January (top) and February (bottom) as a function of year, with underlying histogram of frequency in years (light shading through 1997 only, dark shading through 2004), from NCEP/CPC data. Thin dashed lines show 1978/79. 2003/04 average, and thin dotted lines the one standard deviation envelope. 


\section{Summary and Implications}

The past seven Arctic winters comprised six unusually warm winters, with seven stratospheric major warmings in the past six years. So many major warmings in a short period is unprecedented in the past 50 years, and a cluster of similarly warm winters is indicated only once before, in 19651966 through 1971-1972. Even among the recent warm winters, 2003-2004 winter was remarkable, as highlighted by comparing the synoptic evolution to that in the most similar previous winters.

During the major warming in 2003-2004 the vortex broke down in mid to late December in the upper stratosphere, and began to redevelop by early January. The vortex broke down in early January in the middle stratosphere and at the end of January in the lower stratosphere. The vortex recovered and became unusually strong after late February in the middle stratosphere, and the final warming was late, near the end of April. Middle stratospheric temperatures became uncharacteristically low well before the vortex recovered strength. The lower stratospheric vortex remained extremely small, weak, and warm for the rest of the winter. The rapid, strong recovery of the upper stratospheric vortex and long delay between disruption of the vortex at high and low altitudes were unique. While the strong upper stratospheric recovery is related to the early major warming, so that rapid radiative cooling acted to reform the vortex once wave activity had diminished, the recovery in 2004 was notably stronger than in for previous early (December or early January) major warmings; the 2004 late winter upper stratospheric vortex was the strongest on record. Detailed process studies for 2003-2004 and other prolonged warmings, including analyses of 2D and 3D wave propagation, will help elucidate the processes resulting in the unique characteristics of the 20032004 winter. Understanding these processes is important to diagnosing possible changes in dynamical activity and to improving representations of such processes in climate models

Figure 12. Monthly average north pole temperatures at 50 (green), 10 (black) and $2 \mathrm{hPa}$ (blue) during January (top) and February (bottom) for 1978-1979 through 2003-2004, from NCEP/CPC data. Thin red line is at $195 \mathrm{~K}$. Thin dashed lines show 1978/79-2003/04 average, and thin dotted lines the one standard deviation envelope, in colors corresponding to the levels.

[Austin et al., 2003; Shine et al., 2003; WMO, 2003, and references therein].

Examination of the recent cluster of warm winters in the context of past interannual variability indicates that:

- The largest region of January mean easterlies in the polar middle and lower stratosphere on record was in January 2004 , with monthly mean $60-80^{\circ} \mathrm{N}$ easterlies in January only once hefore since 1979.10 and $50 \mathrm{hPa}$ zonal mean winds in January 2004 were over two standard deviations below average.

- In 2004, February zonal mean winds in the middle and lower stratosphere were among the weakest on record, while upper stratospheric winds were the strongest on 
record in February and March.

- 1998-1999, 2001-2002 and 2003-2004 each had only a few days with temperatures below PSC formation thresholds; six of the last seven years had much lower than usual PSC formation potential; such a pattern might be expected to occur randomly approximately every 850 years.

- In the past seven years, the frequency of occurrence in the past 26 years of winters with extremely low PSC potential nearly doubled.

- $50 \mathrm{hPa}$ north pole temperatures in January and February 2004 were among the highest on record, and with atypically high lower stratospheric temperatures during six of the past seven years.

- Upper stratospheric temperatures after January, and averaged over the 2003-2004 winter, were the lowest on record; middle stratospheric average winter temperatures were also atypically low.

- Four of the seven major warmings in the past six years were unusually early, in December or early January.

- The frequency of major warmings and cluster of warm Arctic winters is unprecedented, with only one previous period (1965-1966 through 1970-1971) with similarly high temperatures, but fewer major warmings.

The series of several very cold and then several very warm Arctic winters may have important implications for diagnosis and attribution of trends and changes in the Arctic circulation. Because the determination of trends depends most strongly on the deviations in the beginning and ending years of the record [e.g., Weatherhead et al., 2004], the previous cold years may have biased calculated temperature trends toward larger decreases, while the recent warm winters would bias them to-wards much less negative trends. Since ozone loss in the lower stratospheric vortex is a large influence on $\mathrm{NH}$ extratropical ozone trends and variability [e.g., Andersen and Knudsen, 2002; Rex et al., 2004 , and references therein], and ozone variations are also closely coupled with temperature variations by dynamical processes [e.g., Salby et al., 2002; Salby and Callaghan, 2002], the high temperatures and limited ozone loss in six of the past seven years are expected to significantly influence apparent $\mathrm{NH}$ ozone trends. Recent studies have suggested a slowdown in ozone decline or beginning of an increase in ozone (both in column and in the upper stratosphere) in some regions starting in the 1996-1998 timeframe [e.g., Fioletov et al., 2002; Newchurch et al., 2003; Steinbrecht et al., 2004a, b; Cunnold et al., 2004]. Such changes appear to be consistent with changes in chlorine loading, and are not limited to the Arctic winter. However, this period does mark a transition between periods of cold/quiescent and warm/active winters; influences of lower stratospheric winter temperature and ozone changes can be global and extend beyond the winter season and throughout the stratosphere [e.g., Fioletov and Shepherd, 2003; Salby and Callaghan, 2004]. Thus, additional care should be taken in the attribution of changing trends during this period.

The cluster of very warm winters following several very cold winters raises the interesting question of whether we may be experiencing a change in the patterns or magnitude of interannual variability in the Arctic stratosphere. While PN99 and Rex et al. [2004] showed evidence that the cold years are becoming more conducive to ozone loss, there has certainly overall been much less ozone loss potential in the past seven years. Pawson et al. [1998] showed apparently discontinuous changes in temperature through the mid-1990s, and Labitzke and Kunze [2004] noted the overall warmer winters in the 1960 s relative to the 1990 s (also noted in the Appendix), and changes in monthly winter temperature trends in the late 1970s. Christiansen [2003] showed evidence for a shift to a stronger, colder vortex regime in the late 1970's; the recent warm winters raise the possibility of a shift back to a more active regime. Corti et al. [1999] noted that the response to anthropogenic forcing may project largely on modes of natural variability, thus such changes could be related to anthropogenic effects. On the other hand, millennial integrations of simple climate models with no anthropogenic forcing do show random distributions of warm winters [e.g., Taguchi and Yoden, 2002], which could result in similar clustering.

Changes in interannual variability, or "regime shift" type changes in dynamical activity, may reflect changes in the patterns of wave activity forcing the stratospheric circulation. It has been suggested that such changes may accompany increasing GHGs [Austin et al., 2003; Shine et al., 2003; WMO, 2003, and references therein] and may be an important factor in lower stratospheric temperature trends and the timing of ozone recovery. Some studies indicate that cooling of the polar stratosphere in winter has been enhanced by changes in dynamical activity; both early ozone recovery related to an increase in dynamical activity, and delayed recovery due to decreased wave activity have been reported in

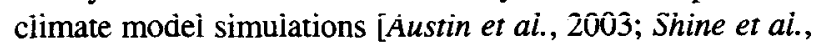
2003; WMO, 2003, and references therein]. Given the large uncertainties in and inconsistent results of current studies, both characterizing and understanding the reasons for recent variability will be important to improving climate models and thus predicting future changes. 
Regime shifts or changes in variability also have important implications for trend detection, since the time required to confidently detect a trend depends on both the variance (year-to-year variability) and the autocorrelation (degree of dependence of one point in the time series on the previous one) [e.g. Weatherhead et al., 1998, 2000; Reinsel et al., 2002], both of which may be affected by changing amounts or patterns of variability. Both larger variance (if interannual variability were greater) and higher autocorrelation (as might be indicated by groups of years with similar characteristics) would increase the time needed to detect a trend. In addition, discontinuous changes may affect the appropriateness of linear or other models for characterizing trends [e.g., Seidel and Lanzante, 2004].

The recent cluster of warm Arctic winters, with 20032004 standing out as the extreme example, raises many provocative questions regarding our understanding of and ability to characterize trends and variability in the $\mathrm{NH}$ winter. By studying in detail both the life-cycles and origins of the stratospheric warmings, and the patterns of tropospheric variability underlying the stratospheric flow, as well as their effects on transport and ozone, we can use this unusual tecent behavior of the stratosphere as a laboratory to test and expand our knowledge of the processes underlying variability in the NH winter stratosphere and possible relations between that variability and changes in climate.

\section{Appendix: Meteorological Datasets and the Pre-Satellite Record}

Several meteorological analyses are available that extend back at least through the 1978-1979 Arctic winter, when operational satellite observations began to be used routinely in these analyses (referred to as "the satellite era"), as well as several more for shorted periods. No single dataset is ideal for all purposes, so we use several of them here for different applications. We show the synoptic evolution during the 2003-2004 winter using NASA's Global Modeling and Assimilation Office's Goddard Earth Observation System-4 (GEOS-4) analyses [e.g. Lin, 2004; Li et al., 2004; Manney et al., 2004], which provide a high-resolution $\left(1 \times 1.25^{\circ}\right.$ latitude $\times$ longitude $)$ state-of-the-art assimilation product. For 1978-1979 to the present, we have examined NCEP (National Centers for Environmental Prediction)/CPC (Climate Prediction Center) objective analyses, NCEP/NCAR (Nvationai Center for Átmospneric Kesearch) Reanalyses (for the lower stratosphere), ECMWF's (European Centre for Medium-Range Weather Forecasts) ERA40 reanalysis through 2001-2002, augmented by operational ECMWF data for the past two winters, and Freie Universitat Berlin (FUB) subjective analyses through 2000-2001; in ad- dition, the record from 1991-1992 through the present has been compared with UK Met Office analyses. Though we focus on the satellite era, since 1978, the ERA-40, REAN, and FUB datasets were also used to examine general characteristics of the flow in earlier years. A more detailed description of these datasets and the consequences of some differences between them to studies of the winter stratosphere is given by Manney et al. [2003, 2004] and Labitzke and Kunze [2004]; PN99 also discuss the use of the FUB data in interannual variability studies.

The REAN dataset, because of the poor vertical resolution in the stratosphere and outdated assimilation model, is not generally recommended for stratospheric studies, and does not extend into the upper stratosphere. While the ERA40 reanalyses show unrealistic vertical temperature structure in the Antarctic lower stratosphere in recent years [Simmons et al., 2004; Manney et al., 2004], such behavior in the Arctic is much less pronounced and limited to the upper stratosphere and the last few years; however, the ERA-40 reanalysis does not cover the past two NH winters. Since the FUB data only cover through the 2000-2001 winter, the NCEP/CPC objective analysis is the only continuing dataset that covers the entire stratosphere and is available for the whole period from 1978-1979; we typically show results from NCEP/CPC for historical records involving this period.

Comparisons of NCEP/CPC analyses with ERA-40/operational ECMWF, REAN, and FUB indicate that the most sensitive diagnostics, such as minimum temperatures and the area below PSC formation thresholds, agree very well for monthly or seasonal averages between NCEP/CPC, REAN, and FUB analyses (e.g., Figure A1); the ERA-40 lower stratospheric temperatures often appear to be biased low (larger area in Figure A1) with respect to the others, with higher average PSC areas over both the years overlapping the NCEP/CPC record and the complete record. However, the patterns of interannual variability are very similar in ERA-40 to those in the other analyses, despite the relative cold bias. Labitzke and Kunze [2004] found significant differences in $30 \mathrm{hPa}$ temperatures during October through January, but much smaller differences in February and March, as well as smaller differences at $50 \mathrm{hPa}$. Our findings also indicate that most of the differences in Figure A1 (and other temperature diagnostics) arise from differences in December and, to a smaller degree, January. During February, when temperatures in recent years were most unusual (section 3), agreement between the analyses is quite good.

Differences are much less between NCEP/CPC, ERA40 and REAN in the diagnostics based on the wind fields; monthly mean $60-80^{\circ} \mathrm{N}$ winds at 50 and $10 \mathrm{hPa}$ are nearly identical, while at $2 \mathrm{hPa}, \mathrm{ERA}-40$ winds are often slightly higher (up to about $5-6 \mathrm{~m} / \mathrm{s}$, but usually much less) than 


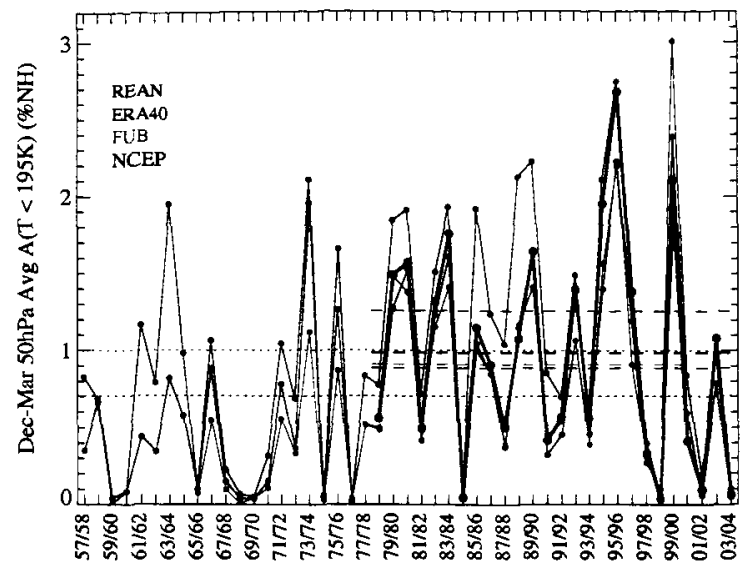

Figure A1. December through March average area with $\mathrm{T} \leq 195 \mathrm{~K}$ at $50 \mathrm{hPa}$ as a function of year, from REAN (blue), ERA-40/ECMWF (red), FUB (green), and NCEP/CPC (black) data. Dotted lines show averages for full period available; dashed lines show average starting with 19781979 , in the period overlapping the NCEP/CPC data.

NCEP/CPC winds; this probably results partially from the use of a balanced wind calculation [e.g., Randel, 1987] for the NCEP/CPC data. The NCEP/CPC objective analysis fields in the upper stratosphere are inferior to the assimilated products for examining detailed synoptic evolution [e.g., Manney et al., 2004], so synoptic fields and detailed day-to-day evolution in earlier years are shown using the ERA-40 reanalyses.

We have chosen to focus on the satellite era because of the better constraints on stratospheric temperatures in the analyses during this period; interannual variability including the earlier period was discussed by $P N 99$. That the pre-satellite period from the late 1950 s through the late 1970 s was overall warmer has been previously noted [Christiansen, 2003; Labitzke and Kunze, 2004, and references therein], and is apparent in Figure A1, as is the previous cluster of warm winters in the late 1960s discussed in the text.

There are numerous caveats in using any of these analyses for interannual comparisons, due to changes in inputs to the assimilation systems (e.g., different satellite observing systems for the stratosphere) and in some cases changes in the analyses [e.g., PN99]. All the diagnostics shown or discussed here have been compared between the NCEP/CPC, ERA-40, REAN, and FUB datasets (the latter two excepting the upper stratosphere), and the particular dataset chosen does not significantly affect any of our conclusions. The dataset shown in each figure is specified in the figure captions.
Acknowledgments. Thanks to the UK Met Office and the British Atmospheric Data Centre for MetO data, the GSFC ACD Science Data System (Eric Nash and Paul Newman) for NCEP/CPC Data, the German Weather Service (Deutscher Wetterdienst, DWD) and ECMWF for ECMWF and ERA-40 and NASA's GMAO for GEOS-4 data; NCEP Reanalysis data were provided by the NOAACIRES Climate Diagnostics Center, Boulder, Colorado, USA, from their web site at http://www.cdc.noaa.gov/. We thank the JPL MLS team, especially Brian Knosp and Robert Thurstans, for technical assistance, data management and computer support, Paul Newman for original routines used to calculate PV, and Crystal Montoya for bibliography database maintenance. Work at the Jet Propulsion Laboratory, California Institute of Technology, was done under contract with the National Aeronautics and Space Administration.

\section{References}

Andersen, S. B., and B. M. Knudsen, The influenceof vortex ozone depletion on Arctic ozone trends, Geophys. Res. Lett., 29, 2013, doi:10.1029/2001GL014595, 2002.

Austin, J., et al., Uncertainies and assessments of chemistryclimate models of the stratosphere, Atmos. Chem. Phys., 3, 127, 2003.

Baldwin, M. P., and T. J. Dunkerton, The stratospheric major warming of early December 1987, J. Atmos. Sci., 46, 2863-2884, 1989.

Chipperfield, M. P., and J. A. Pyle, Model sensitivity studies of Arctic ozone depletion, J. Geophys. Res., 103, 28,389-28,403, 1998.

Christiansen, B., Evidence for nonlinear climate change: Two stratospheric regimes and a regime shift, J. Clim. 16, 36813690, 2003.

Corti, S., F. Molteni, and T. N. Palmer, Signatures of recent climate change in frequencies of natural atmospheric circulation regimes, Nature, 398, 79.9-802, 1999.

Cunnold, D. M., E.-S. Yang, M. J. Newchurch, G. C. Reinsel, J. M. Zawodny, and J. M. Russell III, Comment on "Enhanced upper stratospheric ozone: Sign of recovery or solar cycle effect?" by W. Steinbrecht et al., J. Geophys. Res., 109, doi:10.1029/2004JD004826, 2004.

Dunkerton, T. J., and D. P. Delisi, Evolution of potential vorticity in the winter stratosphere of January-February 1979, J. Geophys. Res., 91, 1199-1208, 1986.

Fioletov, V. E., and T. G. Shepherd, Seasonal persistence of midlatitude total ozone anomalies, Geophys. Res. Lett., 30, doi:10.1029/2002GL016739, 2003.

Fioletov, V. E., G. E. Bodeker, A. J. Miller, R. D. McPeters, and R. Stolarski, Global and zonal total ozone variations estimated from ground-based and satellite measurments: 1964-2000, J. Geophys. Res., 107. 4647, doi:10.1029/2001JD001350, 2002.

Hamilton, K., Interannual variability in the northern hemisphere winter midle atmosphee in control and perturbed experiments with the GFDL SKIHI general circulation model, J. Atmos. Sci., 52, 44-66, 1995.

Labitzke, K., Temperature changes in the mesosphere and stratosphere connected with circulation changes in winter, J. Atmos. Sci., 29, 756-766, 1972. 
Labitzke, K., On the interannual variability of the middle stratosphere during the Northern winters, J. Met. Soc. Japan, 60, 124 139,1982

Labitzke, K., and Collaborators, The Berlin Stratospheric Data Series, CD from Meteorological Institute, Free University Berlin, Berlin, Germany, 2002.

Labitzke, K., and M. Kunze, Stratospheric temperatures over the Arctic: Comparison of three datasets, Meteorol. Zeitschrift, accepted, 2004.

Labitzke, K., and H. van Loon, The Stratosphere, Springer-Verlag, Berlin, Germany, 1999.

Li, S., S. Pawson, B. A. Boville, and S.-J. Lin, Sensitivity of middle atmospheric analysis to the representation of gravity wave drag, J. Atmos. Sci., submitted, 2004.

Lin, S.-J., A vertically Lagrangian finite-v olume dynamical core for global models, Mon. Wea. Rev., in press, 2004.

Manney, G. L., and J. L. Sabutis, Development of the polar vortex in the 1999-2000 Arctic winter stratosphere, Geophys. Res. Lett., 27, 2589-2592, 2000.

Manney, G. L., J. D. Farrara, and C. R. Mechoso, Simulations of the February 1979 stratospheric sudden warming: Model comparisons and three-dimensional evolution, Mon. Weather Rev, 122, 1115-1140, 1994a.

Manney, G. L., R. W. Zurek, A. O'Neill, and R. Swinbank, On the motion of air through the stratospheric polar vortex, J. Atmos. Sci., 51, 2973-2994, 1994b.

Manney, G. L., W. A. Lahoz, R. Swinbank, A. O'Neill, P. M. Connew, and R. W. Zurek, Simulation of the December 1998 stratospheric major warming, Geophys. Res. Lett., 26, 2733-2736, 1999.

Manney, G. L., J. L. Sabutis, S. Pawson, M. L. Santee, B. Naujokat, R. Swinbank, M. E. Gelman, and W. Ebisuzaki, Lower stratospheric temperature differences between meteorological analyses in two cold Arctic winters and their impact on polar processing studies, J. Geophys. Res., 108, 8328, doi:10.1029/2001JD001 149, 2003.

Manney, G. L., et al., Diagnostic comparison of meteorological analyses during the 2002 antarctic winter, Mon. Wea. Rev., submitted, 2004.

Naujokat, B., and K. Labitzke, eds., Solar-Terrestrial Energy Program: Collection of Reports on the Stratospheric Circulation during the Winters 1974/75-1991/92, Scientific Committee on Solar Terrestrial Physics (SCOSTEP), Urbana, Illinois, USA, 1993.

Naujokat, B., K. Kr"uger, K. Matthes, J. Hoffmann, M. Kunze, and K. Labitzke, The early major warming in December 2001 - exceptional?, Geophys. Res. Lett., 29, doi:10.1029/2002GL015316, 2002.

Newchurch, M. J., E. S. Yang, D. M. Cunnold, G. C. Reinsel, J. M. Zawodny, and J. M. R. III, Evidence for slowdown in stratospheric ozone loss: First stage of ozone recovery, J. Geophys. Res., 108, 4507, doi:10.1029/2003JD003471, 2003.

Newman, P. A., E. R. Nash, and J. E. Rosenfield, What controls the temperatures of the Arctic stratosphere during the spring, $J$. Geophys. Res., 106, 19,999-20,010, 2001.

Offermann, D., M. Donner, P. Kneiling, and B. Naujokat, Middle atmosphere temperature changes and the duration of summer, $J$. Atmos. Sol.-Ter. Phys., 66, 437-450, 2004.
Pawson, S., and B. Naujokat, The cold winters of the middle 1990s in the northem lower stratosphere, J. Geophys. Res., 104, 14,209-14,222, 1999.

Pawson, S., K. Labitzke, and S. Leder, Stepwise changes in stratospheric temperature, Geophys. Res. Lett., 25, 2157-2160, 1998.

Perlwitz, J., and H. R. Graf, Troposphere-stratosphere dynamic coupling under strong and weak polar vortex conditions, Geophys. Res. Lett., 28, 271-274, 2001.

Perlwitz, J., and N. Harnik, Observational evidence of a stratospheric influence on the troposphere by planetary wave reflection, J. Clim., 16, 3011-3026, 2003.

Ramaswamy, V., et al., Stratospheric temperature trends: Observations and model simulations, Rev. Geophys., 39, 71-122, 2001.

Randel, W. J., The evaluation of winds from geopotential height data in the stratosphere, J. Atmos. Sci., 44, 3097-3120, 1987.

Randel, W. J., and B. A. Boville, Observations of a major stratospheric warming during december 1984, J. Atmos. Sci., 44, 2179-2186, 1987.

Reinsel, G. C., E. C. Weatherhead, G. C. Tiao, A. J. Miller, R. M. Nagatani, D. J. Wuebbles, and L. E. Flynn, On detection of turnaround and recovery in trend for ozone, J. Geophys. Res., 107, 4078, doi:10.1029/2001JD000500, 2002.

Rex, M., R. J. Salawitch, P. von der Gathen, N. R. P. Harris, M. P. Chipperfield, and B. Naujokat, Arctic ozone loss and climate change, Geophys. Res. Lett., 31, L04116, doi:10.1029/2003GL018844, 2004.

Salby, M., and P. Callaghan, Interannual changes of the stratospheric circulation: Relationship to ozone and tropospheric structure, J. Clim., 15, 3673-3685, 2002.

Salby, M., and P. Callaghan, Interannual changes of the stratospheric circulation: Influenceon the tropics and southern hemisphere, J. Clim., 17, 952-964, 2004.

Salby, M., P. Callaghan, P. Keckhut, S. Goding, and M. Guirlet, Interannual changes of temperature and ozone: Relationship between the lower and upper stratosphere, J. Geophys. Res., 107, 4342, doi:10.1029/2001JD000421, 2002.

Seidel, D. J., and J. R. Lanzante, An assessment of three alternatives to linear tends for characterizing global atmospheric temperature changes, J. Geophys. Res., 109, doi:10.1029/2003JD004414, 2004.

Shine, K. P., et al., A comparison of model-simulated trends in stratospheric temperatures, Q. J. R. Meteorol. Soc., 129, 15651588, 2003.

Simmons, A. J., M. Hortal, G. Kelly, A. McNally, A. Untch, and S. Uppala, ECMWF analyses and forecasts of stratospheric winter polar vortex break-up: September 2002 in the southern hemisphere and related events, J. Atmos. Sci., in press, 2004.

Steinbrecht, W., H. Claude, and P. Winkler, Enhanced upper stratospheric ozone: Sign of recovery or solar cycle effect?, J. Geophys. Res., 109, D02308, doi:10.1029/2003JD004284, 2004a.

Steinbrecht, W., H. Claude, and P. Winkler, Reply to comment by D. M. Cunnold et al. on "Enhanced upper stratospheric ozone: Sign of recovery or solar cycle effect?", J. Geophys. Res., 109, D14306, doi:10.1029/2004JD004948, 2004b.

Tabazadeh, A., M. L. Santee, M. Y. Danilin, H. C. Pumphrey, P. A. Newman, P. J. Hamill, and J. L. Mergenthaler, Quantifying denitrification and its effect on ozone recovery, Science, 288, 1407$1411,2000$. 
Taguchi, M., and S. Yoden, Internal interannual variability of the troposphere-stratosphere coupled system in a simple global circulation model. Part II: Millennium integrations, J. Atmos. Sci., 59, 3037-3050, 2002.

Waibel, A., et al., Arctic ozone loss due to denitrification, Science, 283, 2064-2069, 1999.

Waugh, D. W., and P. Rong, Interannual variability in the decay of lower stratospheric arctic vortices, J. Meteor. Soc. Japan, 80, 997-1012, 2002.

Waugh, D. W., W. J. Randel, S. Pawson, P. A. Newman, and E. R. Nash, Persistence of the lower stratospheric polar vortices, $J$. Geophys. Res., 104, 27,191-27,201, 1999.

Weatherhead, E. C., G. C. Reinsel, and S. B. Andersen, Detecting total column ozone recovery, in Proceedings Quadrennial Ozone Symposium, pp. 83-84, Kos, Greece, 1-8 June 2004, 2004.

Weatherhead, E. C., et al., Factors affecting the detection of trends: Statistical considerations and applications to environmental data, J. Geophys. Res., 103, 17,149-17,161, 1998.

Weatherhead, E. C., et al., Detecting the recovery of total column ozone, J. Geophys. Res., 105, 22,201-22,210, 2000.

WMO, Scientific assessment of stratospheric ozone depletion: 1998, U. N. Environ. Program, Geneva, Switzerland, 1999.

WMO, Scientific assessment of stratospheric ozone depletion: 2002, U. N. Environ. Program, Geneva, Switzerland, 2003.

This preprint was prepared with AGU's $\mathrm{LT}_{\mathrm{E}} \mathrm{X}$ macros v5.01, with the extension package 'AGU'C ' by P. W. Daly, version 1.6b from 1999/08/19. 
Popular summary for:

\title{
"The remarkable 2003-2004 winter and other recent warm winters in the Arctic stratosphere since the late 1990s"
}

\author{
G.L. Manney, K. Krueger, J.L. Sabutis, S.A. Sena and S. Pawson
}

A topic of great concern for climate and the environment is the extent to which ozone depletion will occur in the northern hemisphere. The concept of an "Arctic ozone hole" has been raised by some modeling studies, which suggest that middle atmospheric cooling associated with increasing greenhouse gas concentrations may lead to deeper, colder polar vortices and more chance of ozone destruction. Observational evidence in the 1990s suggested that the polar vortex was becoming cold more often, but it was not possible to determine if this was a trend or a signal of random interannual fluctuations in the circulation. Any greenhouse-gas cooling, which might lead to a colder polar vortex, would interact with ozone in several ways. One of these is through destruction by chlorine (and other) compounds, which is intense in the springtime when the sun reappears (and is the cause of the Antarctic ozone hole). However, with these compounds on the decrease following adoption of international protocols on their emissions, an interesting question is how the stratosphere and polar ozone may change in the future, and how it has changed in the past decades. This study examines the long-term statistics of the stratospheric circulation, showing that six of the past seven winters have been anomalously warm. In particular, the 2003-2004 winter was unusual in many ways, with positive anomalies in almost all measures. The period in the middle 1990s when many winters were cold has been succeeded by a period in which many winters are warm, which is unlikely on the basis of natural variability. This suggests that there is a signal of climate change in the middle atmosphere, with a weaker Arctic vortex in winter.

Steven Pawson

Senior Research Scientist, UMBC/Goddard Earth Sciences and Technology Center Editor, Journal of Geophysical Research - Atmospheres

pawson (agmao.gsfe.nasa.gov

http://userpages.umbc.edu/ pawson

Tel: +13016146159

FAX: +13016146297

Mail: Global Modeling and Assimilation Office, Code 900.3

NASA Goddard Space Flight Center

Greenbelt, MD 20771-0001, USA 